\title{
ENHANCING OMANI UNIVERSITY STUDENTS' WRITING AND STUDY SKILLS: DISCUSSION FORUM MODULE
}

\author{
Hranush Ginosyan and Victoria Tuzlukova \\ Sultan Qaboos University, Oman \\ email: hranushg@squ.edu.om
}

Article received: 10 October 2014

Final proof received: 05 December 2014

\begin{abstract}
This paper reports the results of a study conducted among first-year Foundation Program English Language (FPEL) students, English teachers and FPEL course coordinators at Sultan Qaboos University (SQU) in Oman with the aim to examine the use of Moodle forums for advancing writing and study skills of the students in higher level FPEL courses by participating in asynchronous discussions, interacting with other students and/or the teacher, and exchanging ideas by posting comments. In addition, students', teachers' and course coordinators' perceptions about the discussion forum as an activity in an e-learning environment that can successfully contribute to FPEL curriculum writing and study skills goals and teaching approaches were examined with regard to the attainment of learning outcomes (LOs). Data were collected by interviewing teachers and course coordinators, conducting an online survey for students, monitoring students' participation in forum activities and analyzing the policy documents related to writing and study skills components of FPEL 0560 course. The results of the study corroborate some significant findings of the previous work in the field, and clearly demonstrate that Moodle forums support writing fluency, allow students more time for developing ideas and working on their writing and study skills' assignments. Additionally, forums foster a sense of purpose and community, as well as contribute to communication skills' development of language learners through online language learning environment by responding to online assignments, inviting feedback, commenting on/grading other students' comments, seeking and providing help with purposes of enhancing, reinforcing and researching.
\end{abstract}

Keywords: discussion forums, e-learning platform, learning outcomes, writing and study skills

Sultan Qaboos University is the largest university in Oman which accommodates a substantial number of students every year. The university seeks to promote higher educational standards at Foundation and Post-Foundation levels. Most students entering the university join the Foundation Program which aims at preparing students for further academic study. It offers courses in English, Mathematics and Information Technology. The Foundation Program English Language (FPEL) is the English component of the Foundation Program offered by the Language Center (LC). At the beginning of the academic year, incoming students are placed in six English language proficiency courses that range from courses for complete beginners to those intended for upper-intermediate learners. According to English Foundation Programme Document (2013-2014), these courses are an important part of a learning continuum where courses become more and more complex with greater emphasis on recycling and reinforcement of skills throughout the learning process. English courses are skills-based and students' progress is monitored through a 
combination of continuous and summative assessment measures (p.15).

FPEL implements a learning outcomeoriented curriculum which is built on skills and competencies that students should develop by the end of the course. Mastery of these skills is essential since students are expected to use them extensively in their colleges. To this end, the LC equips its teachers with an array of resources to implement the curriculum in a way that coursework is accomplished and learning outcomes (LOs) are achieved. Although there are sufficient teaching aids and materials, along with various online learning resources that are aligned with the curriculum to target the LOs, there seems to be imbalanced use of the available resources. In simple terms, some resources are overused while others are either underused or completely ignored while it is essential that all the available resources should come into play not only to achieve the discrete LOs but also to continuously enhance students' cognitive skills such as writing and study skills. In the context of FPEL, these skills have become an increasing concern over the past years due to worrying trends in the performance of FPEL students.

The LC has a proven track record in employing technology to support language teaching and learning. All the FPEL courses have a virtual course component supported by Moodle, an e-learning platform which has great potential for supporting conventional classroom instruction, for instance, to do additional work outside the classroom (Brandl, 2005; Dougiamas, 2004). The Moodle platform has been successfully used in the LC, providing both students and teachers with a wide range of resources, such as course outlines, language resources for all four language skills, useful tips, links, etc. However, to what extent is Moodle used FPEL courses to address the course specific
LOs? Which skills are largely addressed by the Moodle-based activities? Which Moodle activities and features can be used specifically to target the writing and study skills LOs? Can the discussion forum module be incorporated into higher-level FPEL Writing and Study Skills course components? And can it contribute to the attainment of the LOs? If yes, how? The collection of answers to these questions may provide clues or directions to the learningoutcome based teaching approach in the FPEL program. It can also contribute to better understanding of the current situation in the FPEL program related to the use of technology in order to enhance FPEL students' writing and study skills. If students' LOs in the FPEL Curriculum Document are our mission, we need to identify and employ all available options to achieve better results.

The FPEL curriculum puts an emphasis on the development of writing and study skills in the learning of English. The lower proficiency level courses focus on the development of general writing skills, such as descriptive writing while higher-level FPEL writing courses, namely FPEL 0560/0603/0604, are centered on academic writing, such as writing academic essays and reports. In the final stage of the writing curriculum, students are engaged in report writing by researching a topic and paraphrasing relevant information from at least three sources. To this end, students are exposed to a wide range of specific study skills and paraphrasing strategies throughout the course. The LC has a strict policy of fighting plagiarism which is viewed as a major crime, and plagiarism checks are carried out through Turnitin internet-based anti-plagiarism software available at www.turnitin.com. Normally, students get penalized if their plagiarism rate generated by the software exceeds $15 \%$. Despite repeated efforts to enhance the writing skills 
in the FPEL, writing remains one of the most problematic skills for FPEL students. Considerably lower writing test scores in comparison with other skill areas provide evidence for this. Although many students manage to pass the final writing exam, it seems obvious that a great number of them still fall short of the required standards for academic writing and study skills.

Over-reliance on classroom instructions in the FPEL writing and study skills curriculum and lack of effective use of the elearning platform could be yet another factor which may contribute to the existing gap between students' writing and study skills needs and curricular requirements. In-house materials focus mainly on higher-level, knowledge-based skills and strategies whereas online, collaborative and interactive learning components have been mostly ignored. This leads to a hypothesis that perhaps there is a need for more balanced use of available resources to enhance the skills of writing and study skills that are so crucial at the higher level FPEL courses. McMullin and Munro (2004) affirm that despite usefulness of all in-house resources and systems in their own rights, a purposebuilt virtual learning environment provides a number of advantages in the context of an institutional use, such as a wide range of functionality, integrated, secure access to all tools and resources and ease of use for staff and students (McMullin and Munro, 2004). Palloff and Pratt (1999) assert that knowledge is primarily generated through the relationships and interactions among people in the online/virtual classroom (Palloff and Pratt, 1999, as cited in McDonald, 2007, p. 8). Thus, adding a virtual course component to higher level Writing and Study Skills courses could be considered as a way to facilitate the report writing process, and consequently, enhance writing and study skills.
The discussion forum module in Moodle is an available resource that is a component of any FPEL course. This e-learning platform enables students and teachers to exchange ideas by posting comments any time when they go online. Due to a variety of types of Moodle-based discussion forums (e.g. a single simple discussion, standard forum for general use, question and answer forum, etc.), they can be used for many innovative purposes, namely writing posts in Moodle, communicating online using texts and other media, commenting on a given topic, asking and answering questions, etc. ("Managing a Moodle course," n. d.). Therefore, they can contribute significantly to successful enhancement of students' communication, language and study skills as well as to community building in an online environment. Moreover, discussion forums, in which such social cues as pace, facial expression and posture are absent, can be liberating for participants and encourage the sharing of more deliberate, less spontaneous, contributions, and viewpoints. Finally, discussion forums in Moodle provide mutual support and/or collaborative learning where students are physically remote ("Discussion Forums in Moodle," n. d.).

The present study aims at examining the extent of integration of the Moodle component in higher level FPEL courses in general and the discussion forum module, in particular. The narrow focus of the study is to explore possibilities of effective integration of a virtual component in higher level writing courses to enhance students' writing and study skills. If one assumes that the lists of discrete LOs from the Curriculum Document represent the teaching/learning goals of the Language Center in essence, then even the best intended efforts to achieve these goals through available materials fall short. All the available resources should be used adequately not only to achieve the 
stated LOs but also to enhance the whole repertoire of LOs in the future.

\section{METHOD}

The study was initiated in February 2014 and concluded in June 2014. It was constructed within the framework of mixed paradigms: constructivist approach and mixed methods research. Since traditional research methods, especially when used independently, have many constraints which make them impossible to fully explore the phenomena in question, their combination will lead to thorough exploration of the focus of the study. As research by Johnson and Onwuegbuzie (2004) discovered, the mixed methods research could be a natural complement to traditional qualitative and quantitative research. Patton (2002) claimed that it could enable the study to use more than one sampling strategy and multiple types of data. He also argued that the constructivist approach could explore the multiple realities built by people and the possible effects of those constructions for their lives and interactions with others. According to him, one of the highlights of this approach is the way social life is interpreted and experienced within certain situational contexts (Patton, 2002). Indeed, the reality of using Moodle discussion forums to enhance writing and study skills is socially constructed, and it was this fact that encouraged the researchers to build a framework that best fits this reality.

The research participants or informants are FPEL 0560 Course Coordinators, FPEL teachers and FPEL 0560 section 180 students since these specific groups are considered as the stakeholders in the process of defining the FPEL writing and study skills syllabus and materials. Coffey and Atkinson (1996) claim that "informants use language to convey particular experiences and meanings (p. 100). Thus, interpretations of each sample population are important in learning about the ways courses were built into Moodle to support language skills. The FPEL coordinators' input was crucial as they are the people who are primarily responsible for setting up the Moodle courses while teachers' contribution was essential because they have first-hand experience of running the Moodle course component. Therefore, based on this experience, they can give feedback on the extent of use and effectiveness of Moodle discussion forums with regard to language skills enhancement, if applicable. As for the students' contribution, it would be essential to learn about their perceptions of effectiveness of discussion forums and evaluation of their strengths and weaknesses, in particular, with regard to the achievement of writing and study skills LOs.

To draw an accurate sample or group that is representative of the FPEL 0560 student population random sampling was used in this study. The decision was made to select any 0560 section taught by one of the researchers as the primary investigator who would carry out this study in order to get first-hand experience of using discussion forums with relation to writing and study skills enhancement. This sampling strategy would ensure that all members of the FPEL 0560 student population have equal chances of being selected. It should be pointed out that these students were mostly 18-19 year old young public school graduates from different regions of Oman. Most of them are computer literate since they take IT courses offered by the Foundation Program and have rather weak writing skills since their writing marks were reported to be the lowest among all language skills. In the case of the course coordinators and teachers, stratified random sampling method was employed. Only FPEL 0560 Course Coordinators and teachers who had experience in using discussion forums in their courses were selected for this study. The rationale behind was the fact that FPEL 
0560 is a course that focuses solely on Academic English after General English prerequisites, and the Writing and Study Skills Course components are centered around the 500-word report. In other words, in this course, students are exposed to academic writing which is largely based on students' research and study skills.

Four major research instruments, namely interviews with FPEL 0560 course coordinators and teachers, online survey for students, students' ongoing discussion forum posts and end-of-term reflection on the Writing and Study Skills course were used to collect data. These research instruments were designed in different stages, and some of them were used synchronously. It should be pointed out that the instruments used in this study allowed for closer investigation of the participants' views, backgrounds competencies and experiences.

The data collection was carried out in two stages. Before the spring semester began, five FPEL 0560 course coordinators and three teachers, who had previously used discussion forums with their students, were invited for interviews. Pre-interview emails were sent to the participants stating the purpose of the study, to seek their consent and to explain the interviewing procedure. The first interviews were unstructured and guided by the research objectives and by the interviews' characteristics described in the study by Al-Zefeiti (2010). According to him, interviews should offer opportunities for flexibility, spontaneity and responsiveness to individual differences and situational changes. The rest of the interviews had a narrow focus to elicit responses to fit in the context of the study. All the interviews were recorded, transcribed, and relevant information was highlighted for extraction of core themes. At a later stage, the extracted themes along with the list of the writing and study skills LOs for the course were used to develop a guided questionnaire for FPEL 0560 students to evaluate the effectiveness of using discussion forums in terms of writing and study skills achievement. This questionnaire investigated five main areas of study, namely general computer efficacy, general study skills, writing skills, course related study skills, open-ended questions about using discussion forums in relation to the LOs. All these areas are directly linked to the work related to FPEL 500-word report which counts as the final writing exam and the questionnaire was to be administered at the end of the course. To ensure validity, the questionnaire was reviewed by a panel of experts which consisted of the LC FPEL Science course coordinator, the head of the Research Committee and a member of Research Committee. Their feedback resulted in a number of relevant items in addition to the points elicited from interviews as well as discarding the repetitive or redundant items. Later, the revised questionnaire was piloted among two FPEL teachers and a few FPEL 0560 students who provided useful comments on the language difficulty level and the time needed for the completion of the questionnaire. This made it possible to create a more user-friendly format of the questionnaire and clarify certain linguistic issues which could be confusing for the respondents.

The last two research instruments were the discussion forum project to be used for ongoing data collection in the spring semester and end-of-term reflection to be done at the end of the course. To complement the FPEL 0560 Science writing and study skills course, a virtual classroom was created for the students participating in the study through the versatile function of the discussion forum in Moodle. This virtual classroom was intended to serve as an open platform for the teacher to post a series of tasks that would reinforce the skills taught in regular classes and provide support outside 
class while for the students this would be a space for voicing their concerns, seeking assistance and clarification, offering help, making suggestions, sharing writings and asking for and giving feedback to peers. It should be noted that this virtual classroom was completely learner-centered since the teacher acted as the facilitator by stepping in only when the questions were directly addressed to her or when necessary.

A set of specific tasks related to the writing and study skills course material was designed to be posted in this virtual environment on a weekly basis. The students were asked to respond to these weekly discussion topics by sharing their experiences. Also, the students were encouraged to post their questions, problems and concerns on the discussion forums if the need arose. Furthermore, this platform was used for sending class reminders and important announcements. Throughout the coursework the students actively participated in 26 discussions which were extended classroom activities related to their report writing project. With 268 posts, the discussion forum module proved to be popular with the students. At the end of the course, the students were asked to reflect on their experiences of using discussion forums in relation to the report writing process. The students did this by completing the online questionnaire discussed previously and by responding to the open-ended questions posted on forum

Data analysis was the next stage of the study. The core themes extracted from the interviews and relevant comments made in the open-ended part of the online survey were grouped and analyzed. The quantitative data (22 valid responses) were computed and arranged in one table representing the responses of the FPEL 0560 students. The data analysis was generated through a special feature on Google forms, the variables were defined and corresponding graphs and charts were generated. The results were arranged into quartiles, after which the upper and lower quartile responses, i.e., the responses that received ratings of $75 \%-100 \%$ and $0 \%$ $25 \%$ on each area of investigation, were identified and highlighted based on the assumption that quartile group observations are significant in making inferences, drawing conclusions or making recommendations (Brown, 1999). Individual comments were grouped, listed and analyzed, and later compared against the corresponding comments students made on Moodle with regard to the same items. Cross-validating statements were separated and combined into one table so that their relationships could be validated.

\section{FINDINGS AND DISCUSSION}

Interviews with FPEL 0560 Course Coordinators and Teachers

The interviews with the course coordinators revealed that Moodle is effectively used by students to practice reading and listening as well as access links to useful websites, articles, educational videos and Clarity grammar exercises. Unfortunately, none of the courses uses discussion forums to enhance writing and study skills. However, some courses, specifically FPEL 0560 Medicine, Science and Agriculture, use discussion forums to post important announcements for students, such as announcing examination dates and times, and sending reminders. FPEL 0560 Commerce and Science have never used discussion forums since they have not found an effective way of using discussion forums in relation to any particular language skill. As mentioned by the course coordinators, in the past FPEL 0560 Medicine, Agriculture and EEALs made an attempt to integrate discussion forums into writing courses, but all those attempts were unsuccessful for different reasons. In one case, students were not responsive, in another case the teacher 
could not manage the forums effectively, and in the other case there was no sustainability. Despite these unsuccessful attempts, all the FPEL 0560 courses expressed interest in integrating discussion forums into their writing courses.

\section{Discussion Forum Reflections}

The information collected from discussion forum reflections yielded a number of valuable findings that seem to corroborate the opinions and beliefs of both LC teachers and FPEL 0560 Course coordinators. According to most students' comments and discussion forum posts, using discussion forums was both interesting and useful because it is a different way of learning and helps them improve their writing and study skills since they need to think carefully before posting their comments. This finding is in line with the claim in literature that discussion forums can be used for many innovative purposes, namely writing posts (messages) on Moodle, reading posts arranged by threads, communicating online, commenting on a given topic, asking and answering questions, etc. (Managing a Moodle course, n. d.). Moreover, the benefits go beyond this since almost all students viewed discussion forums as a helpline which is available any time they seek help when working on their reports. According to the students, they could ask their questions and voice their concerns any time since they knew that help would arrive shortly not only from the teacher but also from their peers.

Discussion Forum Project help me how can I help other student and how can communicate with other student. Also, help me how can discus with other student about some topic and help me to improve me skills in typing.

(Participant 3)

It is useful and helpful because I can help other student and discuss about topic or anything. Also, share the information with other.

(Participant 4)

...In addition, students can get help from others when they face any problem and they can ask questions to get help.

(Participant 11)

From the discussion form we can help other student also we can ask a question and get different opinion.

(Participant 17)

This finding is in complete agreement with the claim that discussion forums in Moodle provide mutual support and/or collaborative learning where students are physically remote (Discussion forums in Moodle, n. d.). Moreover, this helpline was built on trust since the forum was only accessible for this class and the students were comfortable with one another.

It is very good and I like it because we can help us and share anything happening in class and we can communicate together.

(Participant 1)

From the Discussion Forum I find a new family.

(Participant 18)

In line with Palloff and Pratt's (1999) claim that knowledge is primarily generated through the relationships and interactions among people in the online/virtual classroom, most of the students who participated in the study believed that their knowledge expanded due to open interaction with peers since in this space they could ask and answer questions, raise and solve problems and help each other by sharing at any time (Palloff and Pratt, 1999, as cited in McDonald, 2007). This finding further substantiates previous finding in the literature that discussion forums, in which such social cues as pace, facial expression 
and posture are absent, can be liberating for participants and encourage the sharing of more deliberate, less spontaneous, contributions, and viewpoints (Discussion Forums in Moodle, n. d.).

The discussion is interesting and helpful to shred all answers to my question so I like it. (Participant 6)

From the discussion form we can help other student also we can ask a question and get different opinion.

(Participant 14)

While descution form is the most interesting becouse we are free to descuss what we want and get more openoins and solutions with our teacher!!!

(Participant 18)

..., in my opinion, the Discussion forum was very good, and i liked it, because of it we can share our ideas, and our works, and we can help each other together.

(Participant 19)

Discussion Forum Project is very helpful and useful. I like it because it is easy to use and I can use it any tima. Also, it help me.

(Participant 21)

Overall, most students found discussion forums very beneficial because in this way they are exposed to a new way of learning, helping and sharing.

\section{Quantitative data analysis}

The student sample population was fairly representative with a very high turnout of responses (22 responses out of 22 potential responses) since all the students completed the survey. Despite the fact that only one section with 22 students was selected for this study, which is considered as a major limitation, some generalizations can be made based on some cross-validating questionnaire statements and comments made by the students with regard to the topic in question.
On the whole, the results of the survey tended to support the comments made by the sample population in response to the end-ofyear reflection. Also, some ideas expressed by the students in the survey corroborated ongoing discussion forum posts. The synthesis of the results is presented below:

Students' Experiences

The students were asked to label discussion forums in terms of interest, usefulness and share their experiences. Most students (91\%) acknowledged the usefulness of discussion forums with regard to writing and study skills. They claimed that their writing skills and study skills have improved because they had to think a lot before posting on forums, find sources for their peers and share their work with peers. It was observed that these comments were mostly made by active participants of online discussions and this is in complete agreement with Yang and Lin (2010) that students with more participation were more likely to make progress in writing fluency. This finding is also in line with some common reflections discussed in the previous section. Most students were of the opinion that using discussion forums helped them ask questions and ask for help.

Most students appreciated getting different opinions on the question they raised on forums, getting their problems solved and questions clarified. According to some students' comments, discussion forums gave them details about the required project work. It is worth noting here that most students found discussion forums useful because they could post any time at their convenience and even at the weekend.

A similar trend was observed with regard to the interesting nature of discussion forums. Most respondents $(91 \%)$ found discussion forums interesting because this was a new way of learning, helping and sharing. Once again, this claim confirms that discussion forums can be used in an innovative way (Managing a Moodle course, 
n. d.). However, according to two students, discussion forums could be boring when few students participate in the discussions and very often these are the same people.

The students were also asked to give reasons why they posted on discussion forums. Half of the students surveyed claimed posting on forums to seek help from peers and the teacher, some students (36\%) posted to help others and share their ideas, some students $(27 \%)$ posted to respond to the teacher's posts and one student posted to improve his/her typing skills and spelling. All the mentioned reasons for posting have a common aim to generate knowledge through interaction which confirms the claim in the literature that in the online/virtual classroom, knowledge is primarily generated through the relationships and interactions among people (Palloff and Pratt, 1999, as cited in McDonald, 2007, p.15). There were only two students who never participated in discussion forums: one student did not have a computer whereas the other did not have time to post. This leads to identification of some shared views on challenges with regard to using discussion forums. Some students believed that a lack of personal computer was the biggest challenge that some students faced when they were invited to participate in a new discussion. Thus, it can be stated that availability of a computer with a reliable Internet connection contributes to the effective use of discussion forums.

This leads to identification of some shared views on challenges with regard to using discussion forums. As mentioned earlier, some students believed that a lack of personal computer was the biggest challenge that some students faced when asked to participate in a new discussion.

...students can get help from others when they face any problem and they can ask questions to get help. But it is not work evry time because some students have problm with the internet but it is good when we do that on lab.

\section{(Participant 5)}

This brings us to the opposite view shared by most of the respondents that using discussion forums is useful because it can be done any time and from any place, even from their villages at the weekend. Thus, it can be restated that availability of a computer with a reliable connection, of course, ensures effective use of discussion forums. Some students also agreed that everybody's participation in discussion forums is important for effective communication on forums. Even though this cannot be considered as a source of difficulty, it turns into a lack of motivation which results in low turnout of responses on forums. This takes us back to the comments discussed earlier that discussion forums can be boring when the same participants post all the time. If this is true, this evidence further supports the theoretical evidence which demonstrates that students with higher level of motivation tend to post on forums and usually these are the students with higher grades (Managing a Moodle course, n. d.). In light of this, more investigation is needed with regard to these students' overall course grades and writing and study skills project grades, in particular to verify how they match the students' actual forum posts by these students during the project.

The students were also asked to respond to the question whether discussion forums helped them to improve their writing and study skills, and comment on the ways the improvement has been observed. Most students were of the opinion that using discussion forums helped them ask questions and ask for help. Some students were convinced that by using discussion forums they write with fewer mistakes while others claimed that they learnt how to write good essays and a good report. Some students said 
that they learnt to help and share by searching for good sources for themselves and their peers. There was a comment from one student who claimed learning the skill of sending messages through discussion forums.

The survey contained a question whether students would like to use discussion forums in their future courses to which most students responded positively. The most common reasons included a new ways of communication and interaction with classmates, easy access without time limits, benefit from their mistakes as well as from other's mistakes, desire to be part of discussion and give and receive help with the coursework.

I CAN SOLVE MY PROBLEM. AND HELP MY FRIEND PROBLEM.

(Participant 12)

The last but not least important finding of this study supports the concept of ecommunity building through discussion forums (Discussion forums in Moodle, n. d.). Almost all the students acknowledged the fact they belonged to a new community where everybody could trust and rely on each other. As some students commented:

Discussion Forum Project help me how can I help other student and how can communicate with other student.

(Participant 3)

From the Discussion Forum I find a new family.

(Participant 18)

On the whole, the results of the comments made in the open-ended sections of the questionnaires, together with the endof term reflection responses, tended to concur well with the interview findings which corroborate findings of previous research on discussion forum practices with regard to writing and study skills.

\section{CONCLUSION}

This study had an overall aim to explore a new method of improving students' writing and study skills. It sought to explore FPEL 0560 students', 0560 FPEL coordinators and LC teachers' perceptions of using discussion forums in writing courses in order to enhance writing and study skills as well as determine whether all available resources are employed effectively to address writing and study skills. On the one hand, some interesting positive generalizations about discussion forum practices with regard to writing and study skills were made based on the comments made in the open-ended sections of the questionnaires, together with the endof term reflection responses which tended to support the interview findings. On the other hand, the evidence from this study suggests that discussion forums could be challenging for those who do not have computers and internet connection. The evidence also indicates that not all available resources are used effectively to address, let alone enhance, writing and study skills. What is more, the method of synthesis of multiple data was used to reach more valid, tangible and trustworthy findings that would pave the way for the recommendations for using discussion forums as an available resource to enhance students' writing and study skills and improving the FPEL 0560 Writing and Study Skills course.

In sum, these results represent a good step towards formulating new, improved curricular goals in the FPEL, improving the framework for higher level FPEL Writing and Study Skills courses as well as ensuring a balanced use of available materials with relation to writing and study skills.

\section{LIMITATIONS}

Two major limitations could be identified in this study. First, the study focused solely on FPEL 0560 students and will not be extended beyond its scope, which means the results of 
the study would not be generalizable to the LC as a whole. Second, some psychological factors of samples also may constitute a typical limitation. The respondents' willingness to reveal their opinions fully cannot be measured. However, the anonymity of the questionnaires should, to a great extent, guard against this limitation.

\section{RECOMMENDATIONS}

This study had an overall aim to provide information about the extent of using discussion forums by higher level FPEL courses while its narrow focus was on exploring possibilities of using this module effectively to enhance students' writing and study skills. The results of the study have a number of recommendations and implications for practical ways of enhancing students' writing and study skills.

The study clearly indicates the need for the inclusion or better implementation of the discussion forum module as a virtual component of higher level writing and study skills courses. This virtual environment would complement higher level FPEL writing and study skills courses by extending in-class activities and keeping students engaged outside the classroom. All the higher level FPEL courses should have this e-leaning component to adequately deploy the e-learning resources offered by the LC. In this way, a more balanced use of available resources would be ensured.

The discussion forum module has potential pedagogic uses, in particular in relation to enhancing students' writing and study skills. A set of well-designed discussion forum tasks related to the course specific LOs would complement any higher level writing and study skills course by providing students with extra practice opportunities to better achieve the writing and study skills LOs. Moreover, students should be encouraged to respond to online assignments, invite feedback, comment on each other's works, seek and provide help with the purpose of enhancing, reinforcing, researching and giving and receiving feedback to build community and become a part of it as well as to provide insight into effectiveness of instructional methods and objectives, skill use and specific weaknesses of individual students. This kind of practice will develop e-learning culture.

Another important implication is the creation of a class profile through an online diagnostic survey based on course specific LOs. This would make it possible to get the clear picture of students' competencies in terms of course specific LOs and identify the LOs that need to be more intensely addressed. A similar survey should be administered at the end of the semester to evaluate to what extent the LOs have been achieved.

Extensive posting on the forum with minimal teacher input is advocated as discussion forums can contribute significantly to independent learning, successful enhancement of students' communication, language and study skills as well as to community building in an online environment. Even though considerable progress has been made in applying technology in teaching and learning at the LC, students should be encouraged to be exposed to on-line learning environment more frequently. This type of practice will contribute to enhancement of students' study skills.

Teachers should be aware that for many students, the teacher may be the primary role model from whom they have an opportunity to develop their skills. Therefore, teachers should present themselves as an active member of the virtual community, for instance, they should respond to questions or problems raised by a student, comment on students' responses, and recommend some interesting and useful 
articles for students' projects but without dominating the discussions.

All in all, discussion forums could be an integral part of any class to serve a number of purposes. The teachers can send out important announcements, reminders and additional tasks if anything has been missed out in the regular class. Students should be able to raise their questions and concerns by starting a new discussion at any time without having to wait for their next class. Finally, apart from serving as an aiding tool to enhance certain skill areas of students, discussion forums provide social interaction and collaboration which are vital in this era of advanced technologies.

\section{ACKNOWLEDGEMENTS}

We are truly thankful to the administration of the Language Center of Sultan Qaboos University and to the Professional Development and Research Unit for supporting this research. Our thanks also go to the Foundation program students, teachers and course coordinators for their participation.

\section{REFERENCES}

Al-Zefeiti, A. (2010). A stakeholder evaluation of English for Academic Purposes (EAP) writing programme. Unpublished $\mathrm{PhD}$ thesis. University of Bristol.

Brandl, K. (2005). Are you ready to Moodle? Language Learning \& Technology. 9(2), pp. 16-23. Retrieved October 12, 2013 from http://llt.msu.edu/vo19num2/pdf/review1 .pdf.

Brown, J. D. (1999). Understanding research in second language learning: Cambridge language teaching library. Cambridge: Cambridge University Press.

Coffey, A. \& Atkinson, P. (1996). Making sense of qualitative data:
Complimentary research strategies. Thousand Oaks: Sage.

Discussion Forums in Moodle. Learning technology and innovation. Retrieved October 10, 2013 from http://clt.lse.ac.uk/moodle/discussionforums.php

Dougiamas, M. (2004). Moodle: A virtual learning environment for the rest of us. TESL_EJ. 8(2). Retrieved October 10, 2013 from http://teslej.org/ej30/m2.html.

English foundation programme document. (2013-2014). Sultan Qaboos University: Language Centre, pp. 15-24.

Johnson, R. \& Onwuegbuzie, A. (2004). Mixed methods research: a research paradigm whose time has come. Educational Researcher, 33(7). pp.1426.

Managing a Moodle course. (n. d.) Retrieved October 10, 2013 from http://docs.moodle.org/24/en/Forum_sett ings.

McDonald, J. (2007). The role of online discussion forums in supporting learning in higher education. Retrieved October 16, 2013 from http://eprints.usq.edu.au/3588/.

McMullin, B. \& Munro, M. (2004). Moodle at DCU. Dublin City University. Retrieved October 5, 2013 from http://odtl.dcu.ie/wp/2004/odtl-200401.html.

Patton, M. (2002). Qualitative research and evaluation methods. CA, Thousand Oaks: Sage Publications, Inc.

Yang, Y. \& Lin, N.C. (2010). Internet perceptions, online participation and language learning in Moodle forums: A case study on nursing students in Taiwan. Procedia-Social and Behavioral Sciences. 2(2), pp. 26472651. Retrieved October 10, 2013 from http://www.sciencedirect.com/science/ar ticle/pii/S1877042810004283 
Ginosyan and Tuzlukova, Enhancing Omani University students' writing and study skills 